\title{
Editorial for the Special Issue on Discontinuous Fiber Composites, Volume II
}

\author{
Christoph Kuhn ${ }^{1, *(\mathbb{D})}$ and Tim A. Osswald ${ }^{2, *}$ (D) \\ 1 Volkswagen Group of America, Chattanooga, TN 37416, USA \\ 2 Department of Mechanical Engineering, University of Wisconsin Madison, Madison, WI 53706, USA \\ * Correspondence: christoph.kuhn@vw.com (C.K.); tosswald@wisc.edu (T.A.O.)
}

Citation: Kuhn, C.; Osswald, T.A. Editorial for the Special Issue on Discontinuous Fiber Composites, Volume II. J. Compos. Sci. 2021, 5, 71. https://doi.org/10.3390/jcs5030071

Received: 25 February 2021

Accepted: 26 February 2021

Published: 5 March 202

Publisher's Note: MDPI stays neutra with regard to jurisdictional claims in published maps and institutional affiliations.

Copyright: (c) 2021 by the authors. Licensee MDPI, Basel, Switzerland. This article is an open access article distributed under the terms and conditions of the Creative Commons Attribution (CC BY) license (https:// creativecommons.org/licenses/by/ $4.0 /)$.
This Special Issue on discontinuous fiber composites and its published papers, like its predecessor, give the polymer engineer and scientist an insight into challenges and research topics in the field of discontinuous fiber-reinforced composites. This Special Issue addresses a number of current topics from industry and academia, displays the latest achievements in the field and further introduces novel research topics as inspiration for future work.

In various industrial applications, discontinuous fiber-reinforced composites have been successful due to their wide range of properties and advantages regarding, for example, their mechanical property to weight ratio, cost-efficient and flexible production and recyclability. These advantages over traditional materials like steel and aluminum have been continuously improved by academic and industry research.

A prominent research topic with discontinuous fiber-reinforced composites is the understanding and prediction of the process-related fiber microstructure inside the composite. The introduction of discontinuous fibers, such as glass, carbon or natural fibers into a polymer resin, synergistically creates a composite material superior to the individual components. Next to the fiber's material properties, the final product's properties rely strongly on the inner fiber microstructure, e.g., orientation, content and length. Due to process-induced effects, phenomena like fiber reorientation, attrition and even fiber-matrix phase separation occur. Examples of continued work on changes in fiber microstructure inside a component, presented in this special edition, are shown by the work of Simon et al. [1] on direct fiber simulation of orientation development during flow, and the work of Chang et al. [2] on the local fiber structure with their investigations into fiber length distribution inside injection molded plaques.

For decades, particle orientation has been the major focus due to the importance of the process-induced microstructure on mechanical component behavior. Fiber alignment during processing leads to regional part anisotropy, which has created great opportunities for mechanical applications if these effects are understood and accounted for. Hence understanding and predicting the final microstructure is of significant importance for successful application.

With the introduction of computers, the first simulative models were created to predict the changes of fiber orientation during processing with the help of phenomenological models [3]. With the increase in computational capacity and improved models, simulations have increased both in accuracy and computational speed with great improvements for part development. A comprehensive review of the history of these phenomenological fiber orientation models by Kugler et al. [4] is included in this Special Issue. Current research is still focused on further understanding and improving the prediction of fiber properties during various established and novel processes, from injection and compression molding to extrusion and additive manufacturing. On the side of simulative models, improved prediction accuracy and faster development times are the focus of research. A fitting example of faster development times is Willems et al.'s new method to calibrate the fiber orientation model parameter for injection molding simulations [5]. Improvements in accuracy 
continually lead to newer simulation models. Kugler et al. present their latest approach with a novel flow-dependent fiber orientation model [6]. Another example is shown by Hopmann et al., where trained neuronal networks are applied in a metamodeling approach to optimize part performance with a compression molded sheet molding compound (SMC) in the preforming stage [7]. Further, Kuhn and Wehler present a phenomenological model on fiber-matrix-phase separation during compression molding, a model to predict changes in fiber content distribution inside a component [8].

With increasing computational power in recent years, detailed simulations on particle level with fiber models inside a polymer flow became feasible, thus enabling detailed studies of fiber behavior, regarding orientation, attrition and fiber-matrix phase separation $[9,10]$. The latest advances with this direct fiber simulation approach are presented in this Special Issue [1,2]. Kech et al. present their investigations on the significance of fiber parameter variations for the pARD-RSC orientation model in a shear cell simulation with a similar model [11]. Further, Teuwsen et al. [12] successfully compare fiber orientation predictions from a mechanistic fiber model with compression molded carbon fiber epoxy composites via computed tomography. Chang et al. [12] apply the detailed fiber simulation to validate fiber breakage experiments inside a simple shear flow. Meyer et al. [13] applied a direct fiber simulation approach to successfully identify fitting parameters for phenomenological fiber orientation models. Morais et al. [14] present their research on carbon nanotube (CNTs) composites and investigate the influence of local nanofiber microstructure on electrical conductivity. They show that with optimized microstructure, polymers can be designed as electrically conductive and hence, can be suitable for metal substitution and implementation in complex component design.

Next to the traditional processing techniques like injection and compression molding, research on fiber-induced properties within the field of additive manufacturing have increased in recent years. Heckner et al. present their study of fiber-filled powders in selective laser-sintering processing [15]. While this process is comparably different to meltbased processing techniques, a process-induced fiber microstructure during the recoating process, and hence an anisotropic component behavior is also found in this process. Knorr et al. show the application of additive manufactured injection molding tools for small series manufacturing and compare them to steel and aluminum tooling. In this application, both the tools and the later parts are manufactured with different fiber-reinforced composite materials [16]. This area of additive tooling shows how discontinuous fiber microstructure is affected by the heat transfer during flow and cooling of the reinforced melt [16].

The latest industry trends with fiber-reinforced composites have been increasingly focused on the fields of recycling where the reuse of both polymer and matrix materials, and the understanding of recycled material behavior are key factors for successful product application. The reduction of carbon emissions through the reuse and recycling of materials is a key factor for a more sustainable future. Wellenkoetter et al. [17] present a novel approach to incorporate recycled fiber and matrix material in an injection molding process via direct fiber feed. Ghossein et al. present a novel wet laying process for the efficient reuse of recycled carbon fibers [18]. Chen et al. further present their latest developments on recyclable thermotropic liquid crystalline polymer and glass fiber composites [19]. Pulipati and Jack present their work on polymer foam structures made from recycled polyethylene and polypropylene [20].

This Special Issue relates not only to a variety of materials, but also to different processes, such as injection and compression molding as well as additive manufacturing. The set of papers in this issue can help advance discontinuous fiber-reinforced composites by contributing to the overall understanding of microstructure development during processing. 


\section{References}

1. Simon, S.A.; Bechara Senior, A.; Osswald, T. Experimental Validation of a Direct Fiber Model for Orientation Prediction. J. Compos. Sci. 2020, 4, 59. [CrossRef]

2. Chang, T.-C.; Bechara Senior, A.; Celik, H.; Brands, D.; Yanev, A.; Osswald, T. Validation of Fiber Breakage in Simple Shear Flow with Direct Fiber Simulation. J. Compos. Sci. 2020, 4, 134. [CrossRef]

3. Folgar, F.; Tucker, C.L. Orientation Behavior of Fibers in Concentrated Suspensions. J. Reinf. Plast. Compos. 1984, 3, 98-119. [CrossRef]

4. Kugler, S.K.; Kech, A.; Cruz, C.; Osswald, T. Fiber Orientation Predictions-A Review of Existing Models. J. Compos. Sci. 2020, 4, 69. [CrossRef]

5. Willems, F.; Reitinger, P.; Bonten, C. Calibration of Fiber Orientation Simulations for LFT-A New Approach. J. Compos. Sci. 2020, 4, 163. [CrossRef]

6. Kugler, S.K.; Dey, A.P.; Saad, S.; Cruz, C.; Kech, A.; Osswald, T. A Flow-Dependent Fiber Orientation Model. J. Compos. Sci. 2020, 4, 96. [CrossRef]

7. Hopmann, C.; Neuhaus, J.; Fischer, K.; Schneider, D.; Gonçalves, R.L.P. Metamodelling of the Correlations of Preform and Part Performance for Preform Optimisation in Sheet Moulding Compound Processing. J. Compos. Sci. 2020, 4, 122. [CrossRef]

8. Kuhn, C.; Wehler, S. A Force-Balanced Fiber Retardation Model to Predict Fiber-Matrix-Separation during Polymer Processing. J. Compos. Sci. 2020, 4, 165. [CrossRef]

9. Kuhn, C. Analysis and Prediction of Fiber Matrix Separation during Compression Molding of Fiber Reinforced Plastics. Ph.D. Thesis, Friedrich-Alexander-Universität Erlangen-Nürnberg, Erlangen, Germany, 2018.

10. Londoño-Hurtado, A. Mechanistic Model for Fiber Flow; University of Wisconsin-Madison: Madison, WI, USA, 2009.

11. Kech, A.; Kugler, S.; Osswald, T. Significance of Model Parameter Variations in the pARD-RSC Model. J. Compos. Sci. 2020, 4, 109. [CrossRef]

12. Teuwsen, J.; Hohn, S.; Osswald, T.A. Direct Fiber Simulation of a Compression Molded Ribbed Structure Made of a Sheet Molding Compound with Randomly Oriented Carbon/Epoxy Prepreg Strands-A Comparison of Predicted Fiber Orientations with Computed Tomography Analyses. J. Compos. Sci. 2020, 4, 164. [CrossRef]

13. Meyer, N.; Saburow, O.; Hohberg, M.; Hrymak, A.N.; Henning, F.; Kärger, L. Parameter Identification of Fiber Orientation Models Based on Direct Fiber Simulation with Smoothed Particle Hydrodynamics. J. Compos. Sci. 2020, 4, 77. [CrossRef]

14. Morais, M.V.C.; Marcellan, M.; Sohn, N.; Hübner, C.; Henning, F. Process Chain Optimization for SWCNT/Epoxy Nanocomposite Parts with Improved Electrical Properties. J. Compos. Sci. 2020, 4, 114. [CrossRef]

15. Heckner, T.; Seitz, M.; Raisch, S.R.; Huelder, G.; Middendorf, P. Selective Laser Sintering of PA6: Effect of Powder Recoating on Fibre Orientation. J. Compos. Sci. 2020, 4, 108. [CrossRef]

16. Knorr, L.; Setter, R.; Rietzel, D.; Wudy, K.; Osswald, T. Comparative Analysis of the Impact of Additively Manufactured Polymer Tools on the Fiber Configuration of Injection Molded Long-Fiber-Reinforced Thermoplastics. J. Compos. Sci. 2020, 4, 136. [CrossRef]

17. Wellekötter, J.; Resch, J.; Baz, S.; Gresser, G.T.; Bonten, C. Insights into the Processing of Recycled Carbon Fibers via Injection Molding Compounding. J. Compos. Sci. 2020, 4, 161. [CrossRef]

18. Ghossein, H.; Hassen, A.A.; Kim, S.; Ault, J.; Vaidya, U.K. Characterization of Mechanical Performance of Composites Fabricated Using Innovative Carbon Fiber Wet Laid Process. J. Compos. Sci. 2020, 4, 124. [CrossRef]

19. Chen, T.; Kazerooni, D.; Ju, L.; Okonski, D.A.; Baird, D.G. Development of Recyclable and High-Performance In Situ Hybrid TLCP/Glass Fiber Composites. J. Compos. Sci. 2020, 4, 125. [CrossRef]

20. Pulipati, D.P.; Jack, D.A. Strength Prediction Sensitivity of Foamed Recycled Polymer Composite Structures due to the Localized Variability of the Cell Density Distribution. J. Compos. Sci. 2020, 4, 93. [CrossRef] 